\title{
A Mobile Electronic Toll Collection for E-Commerce Applications
}

\author{
Chin E. Lin ${ }^{1,2}$ and Ling Yan $\mathrm{Bi}^{2}$ \\ ${ }^{1}$ Department of Aeronautics and Astronautics, National Cheng Kung University Tainan, Taiwan, \\ chinelin@mail.ncku.edu.tw \\ ${ }^{2}$ School of e-Commerce, South China University of Technology Guangzhou, \\ China, chinelin@scut.edu.cn, blingyan@scut.edu.cn
}

Received 28 February 2007; received in revised form 16 October 2007; accepted 11 January 2008

\begin{abstract}
This paper establishes a new mobile electronic toll collection (m-ETC) by integrating mobile communication with radio frequency (RF) communication on microprocessor control with an e-commerce business model. A simple ETC system architecture and protocol for e-transactions from vehicles to toll stations is proposed to complete toll interaction on wireless environment. A software flow through Internet is developed to link from toll station roadside units (RSU) to car units. A car unit (CU) for vehicle, a pair of roadside units (RSU), and an eCenter are established. A data flow and an interaction protocol are created. The proposed m-ETC system can be applied to different toll/charge systems with appropriate hardware and software. Some simulation test results verify basic system performance on ETC applications. A new business model for the proposed m-ETC is organized and discussed with feasibility analysis in e-commerce demonstration.
\end{abstract}

Key words: Mobile e-commerce (m-commerce), Mobile and radio communication, Mobile electronic toll collection (m-ETC), e-Transaction, Circuit hardware 


\section{Introduction}

Mobile communication has become a livelihood technology to be widely adopted for added value applications. While e-commerce is introduced to elevate daily commercial interactions from the conventional business concept, mobile e-commerce (m-commerce) is another trend to develop suitable technologies for new applications under free mobility condition. M-commerce is defined as a commerce behavior by mobile stations [12], [16]. Mobile stations include wireless phone, wireless handheld computer, laptop, personal message pager device and personal digital assistants (PDA) [3], [4]. M-commerce presents the function of personal mobility, operational flexibility, and interactive availability with various function capabilities. Due to the high population of mobile communication users, $m$ commerce is an emerging demand to those mobile users in the near future. In Taiwan, the National Communication Committee (NCC) has statistics report of 22.8 million mobile users in second quarter 2006. It is extremely high percentage on this 23 million population island (Site 1). In China, the official statistics has reported 487.4 million mobile users in first quarter 2007 from Internet news April 30, 2007. It is 38\% of total population in China. The mobile phone users are still increasing in both areas, matching with the worldwide trend. As mobile communication has been well accepted by the users, mobile services should not only limited within personal communications, but also extended into wider added value applications in decreasing fare. Since mobile communication itself represents freedom from fixed locations, the adoption of mobile communication to transportation system is an emerging application.

Focusing on the development of Intelligent Transportation Systems (ITS) [8], road information acquisition and data processing to road users are the most important role of study. In China, road construction and personal vehicle are two highest expansion and increase in the world. Total mobile phone users is much more than total vehicle numbers at present in China and Taiwan, or even possibly to the whole developed and developing countries. The use of mobile phones to enhance ITS is viable and feasible. Toll collection is adopted to facilitate further investments as a chain reaction to improve ground transportation system. How to adopt efficient toll collection methods will become the most concerns in the national transportation administration in China. Technologies on all different demands are studied and designed to fit the toll collection requirements. Among them, unmanned toll collection is one of the urgent issues to deal with and solve in many countries due to manpower cost. New methods from new technologies are developed to solve ITS problems.

Methods for toll collection have been developed since 1980's including microwave system, optical system and recent RFID system. Today, some technologies are quite mature for worldwide realizations. Microwave systems have been broadly used in North American [8] and some European countries. Microwave system requires delicate antenna arrangement and communication environment setup to appropriate installations [6], [11]. Antenna is improved to elevate the working efficiency for fast vehicle flow [11]. Reliability is dependent upon antenna performance. Recent implementations in Melbourne, Australia [17] and Ontario, Canada [18] have adopted microwave technology to improve highway toll efficiency in complete electronic operation. The investment on the City Link Toll Road at Melbourne was about A\$ 2 billion began construction in 1996 creating $22 \mathrm{~km}$ expressway linking to airport [17]. The 407 Express Toll Route at Ontario started construction in 1997 with CA $\$ 1.6$ billion for $108 \mathrm{~km}$ highway [18]. The capital investments are very high to pursue benefits from highway convenience.

New telematics technology to read road information as well environment condition has been developed for toll collections [1]. Based on road side message exchange concept, the dedicated short range communication (DSRC) technology is developed to adopt radio frequency (RF) communication to broadcast road information to vehicle [20]. The RF technology can be applied with mobile communication in location and tracking for ITS [5].

Recently, RFID is a new emerging technology in ETC applications [21]. Successful tests have supported to its spread implementation to the transportation system shortly [15]. RFID has its property superiority on small size, wide range and precise built-in information. The test progress has proven RFID to be a feasible solution in ITS, especially for ETC. However, either microwave system or RFID system relies on very expensive initial investments. Prepaid charge system is applied to the road users.

Since mobile communication has been accepted as a personal device in the world, its mobility characteristics with acceptable price is credited for extensive personal uses. The percentage of vehicle drivers to use mobile phones is rising due to its convenience. A parking lot surveys in 2007 in Taiwan and in China on the driver behavior with mobile phones have resulted in very high percentage of linkage between them. This reflects very high percentage of vehicle drivers using cell phones. This survey collects more than ten thousands samples from 22 parking lots in 7 major cities. The motivation to develop m-commerce or m-ETC solution in conjunction with mobile communication is inspired and strongly encouraged. The combination of mobile communication with ETC can be a useful idea to toll center, road users, and system providers to become a new added value application [12]. In mobile phonic systems, the infrastructure is already well coverage to validate most users in many areas. Added value developments are efforts to elevate mobile communication into new era of technology applications. New method adopting mobile technology to solve ITS problem in creating new commerce mechanism is developed. The users may receive benefits from its mobility and convenience with different e-commerce functions [12], [16]. 
For toll collection, the e-transaction needs to be established in conjunction with finance corporations or banks. Surveys show that different countries providers different strategies in offering the e-transactions under m-commerce system. In China, bank system accepts e-transaction through mobile system providers. In many countries, the bad debts or irrecoverable credits from mobile bills are huge burden to the system providers. However, the finance corporations or banks, who issue credit cards, would still appreciate the new m-commerce based on specially designed program and contract. Under such circumstances, the proposed m-ETC can become a viable solution. An Internet e-interaction system should be created for the proposed m-ETC system.

For most methods for e-commerce and m-commerce, there are demands of matching hardware and software to meet the system requirements for user identification, function recognition, interaction authentication, data storage and processing. Hardware constrained by firmware may be a consolidate solution to protect any feasible implementation. A complete system design should include firmware and hardware integration to realize the proposed system concept. The ETC system involves some technical standards for interactions between the users and system hardware and software. Standards in conjunction with pricing model are correlated factors to impact the road congestion and toll efficiency [14]. ETC characteristic is an important task to public e-commerce performance.

For personal mobility, any kind of wireless communication can be considered. Radio frequency (RF) communication has been used for several decades [20], [5]. VHF data link (VDL) is developed as an important media for long range or short range data communication depending on their power setting and antenna arrangement [20]. Its system infrastructure, operation and maintenance are tedious and expensive engineering work but unreliable coverage to wide-spread users. Short distance to specific use will be feasible for RF adoption. Wireless communication based on 802.11, RF and others may be capable for excellent performance for high data rate, but are limited in short range transmission [5] [19]. Besides, blue tooth is one emerging technology to adopt. However, blue tooth can not open to more users due to its limited connecting protocol. The wireless technologies are known as 100 meters or less. The extension of communication coverage requires a complete plan of networking, such as mobile base stations. In short distance and short message interaction between two or more devices, wireless communication can be adopted. Another problem might be considered on the number of users. The frequency division multiple access (FDMA) technology has the defect to occupy frequency channel by each user. The time division multiple access (TDMA) and code division multiple access (CDMA) overcome these defects to use frames and slots for each packet data [3], [10], [9]. Users will not occupy certain frequency channels, but share the spectrum and quality of service (QoS) to all users 2]. Mobile communications, of the second generation (2G) of Global System of Mobile communication (GSM), the $2.5 \mathrm{G}$ of General Packet Radio Service (GPRS) [9], the $3 \mathrm{G}$ of wide band communication, and beyond 3G (B3G) of higher performance system, are introduced [3], [5], [7]. Base station infrastructure investments for wider coverage have been well established in most developing and developed countries [7]. The adoption of mobile communication can be a feasible choice in the future development that benefits the infrastructure for added value services. Less initial investment can be avoided. An integration of two communication means using mobile communication in wide range coverage and RF for short distance data exchange is considered as a new ETC solution.

This paper proposes a feasible solution of ETC using mobile communication infrastructure to achieve toll collection as part of m-commerce. The proposed m-ETC system protocol is constructed by GSM, RF module, microprocessor (AT89C52) [13] and the related hardware for circuit design and implementation. The proposed m-ETC contains car unit (CU) and road side units (RSU) to exchange the toll message between vehicle and toll center. A toll protocol is studied and established to fast complete a toll transaction within driving through period. From campus road tests, the proposed m-ETC system is verified with some feasibility data in GSM framework [4], [9], [7]. The applications of the proposed m-ETC system have been tested in freeway entrance controls and parking lots. The system performance with feasible operation data is presented. In this paper, system installation is designed and fabricated in laboratory with complete road tests. Technologies such as Car Unit (CU) and Road Side Unit (RSU) using microprocessor to exchange message between RF transceivers are involved. The communication means of RF and GSM in hierarchical structure is linking to a transaction and authentication process in a server with software implementation.

\section{System Framework}

In this paper, a new ETC system design using mobile communication for freeway and parking lot application is proposed. The m-ETC system configuration is shown in Figures 1, 2 and 3 for different applications as solutions for freeway entrance gate control, toll station control and parking lot control. In the proposed m-ETC system, there are key components to develop, such as the Roadside Transmitter (RS-TX), the Roadside Receiver (RS-RX) and the Car Unit (CU). In the m-ETC system design, both systemic hardware as well as m-commerce software is discussed in details. A business model is recommended. 


\section{Freeway}

Northbound

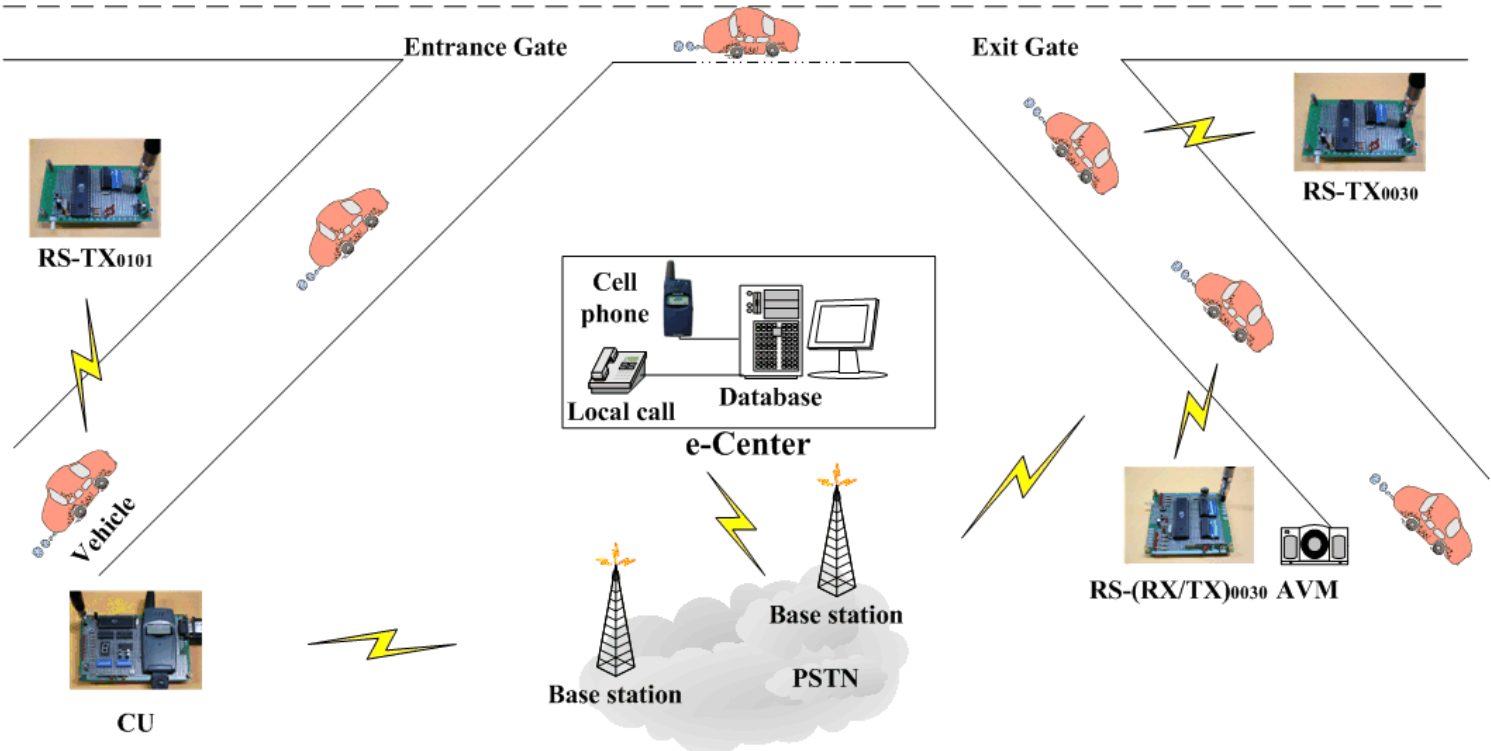

Figure 1: Architecture of the m-ETC System for freeway entrance gate control.

The CU includes identical electronic transceivers as RS-TX and RS-RX to interact with road side units using a microprocessor for digital signal processing [2], [13]. It is a device on the vehicle. On the business model, the Car Unit should be issued under certain mobile contract. The functions of CU-TX and CU-RX in the Car Unit will transmit and receive message from the Roadside Units. The Roadside Transceiver (RS-TX) will transmit an interrogation message to active the Car Unit to start the GSM handset for ETC electronic transaction as a part of m-commerce. While the Toll Center accepts the transaction, the GSM handset will receive an approve code for the Car Unit. The Car Unit will acknowledge to Roadside Unit at appropriate instant of passing-by the Roadside Receiver (RS-RX) to complete the acknowledgement. The Roadside units are connecting to the e-Center via wired or wireless technology into Internet. Message connecting via GPRS onto Internet will be a good means to link to the e-Center for transaction. [9].

Freeway
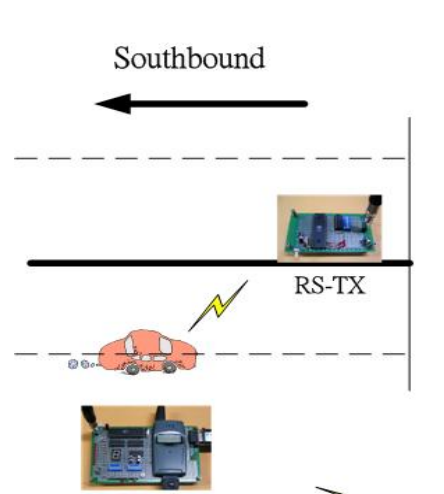

$\mathrm{CU}$
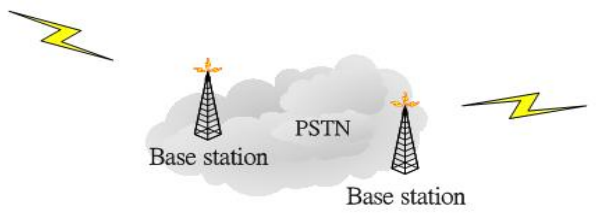

Freeway Toll Station

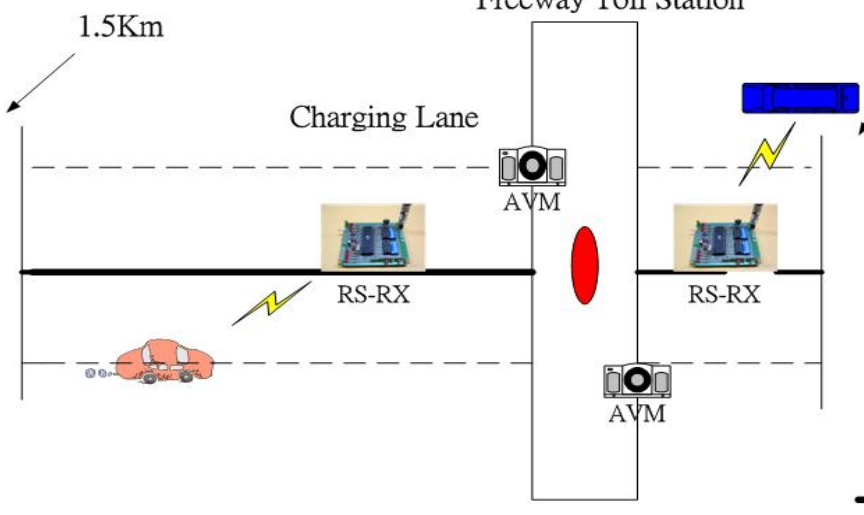

Northbound

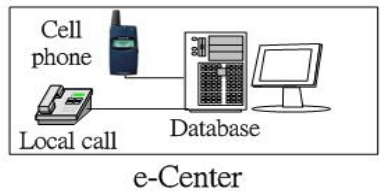

Figure 2: Architecture of the m-ETC System for freeway toll station control. 


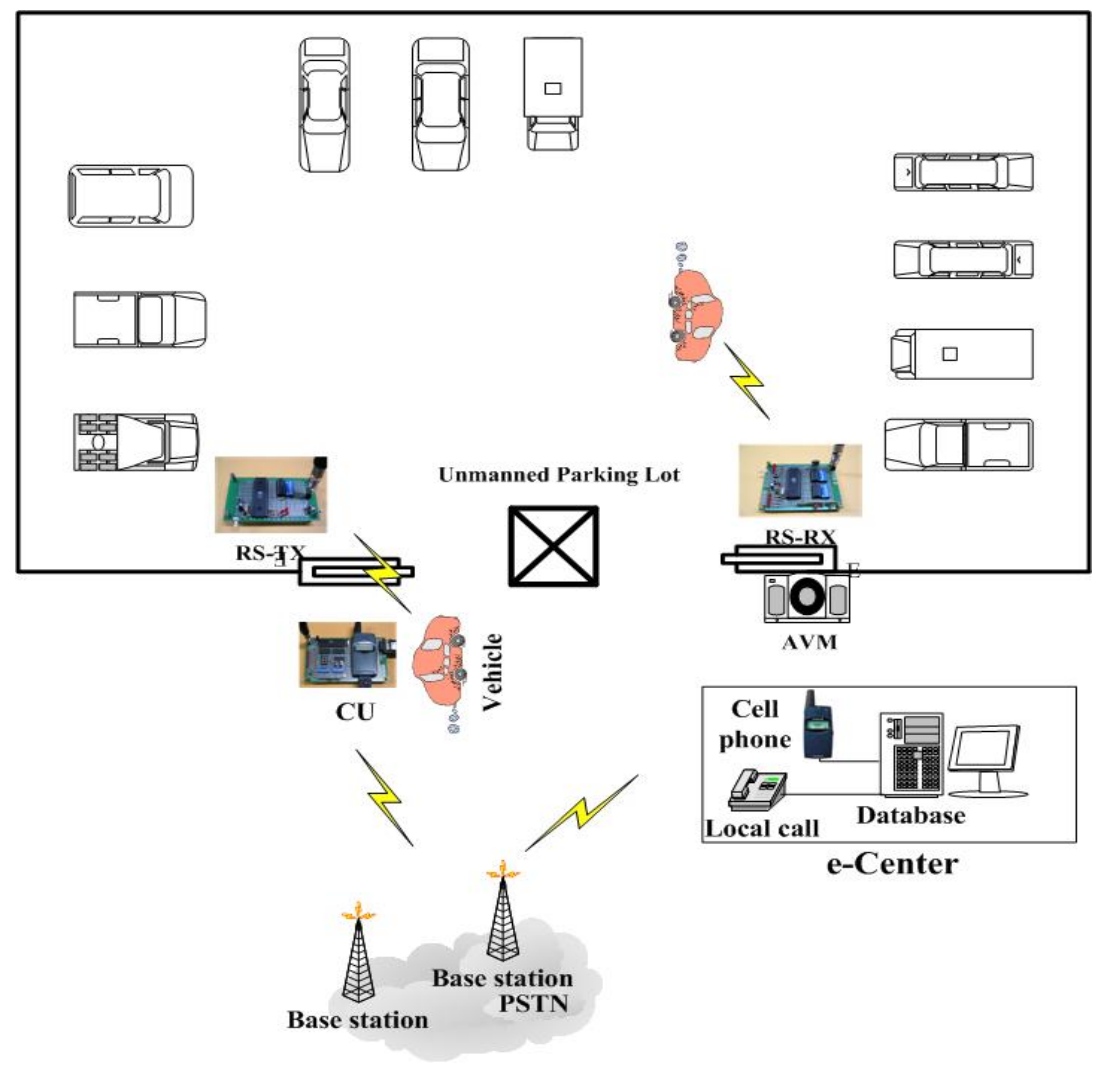

Figure 3: Architecture of the m-ETC System for parking lot.

вятा
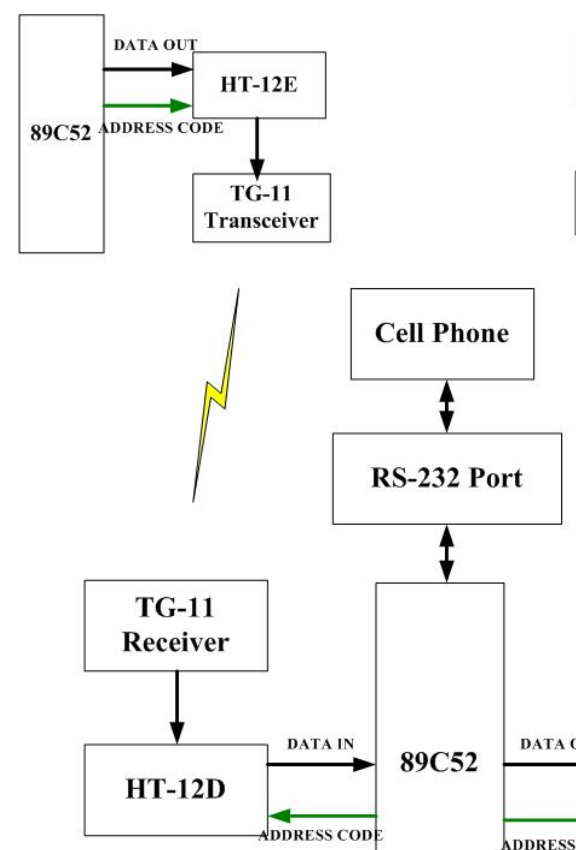
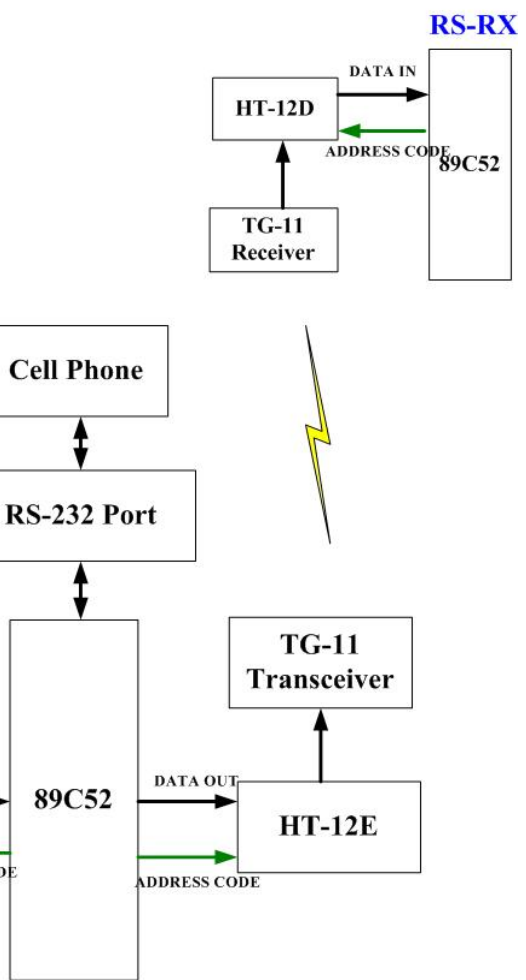

Car-Unit

Figure 4: Architecture of CU, RS-RX, RS-TX. 
In Figures 1 to 3, three different applications will result in three different ways of m-commerce transaction. In this paper, GSM system handset with SIM is generally considered as personal ID code to verify the m-commerce of $\mathrm{m}$ ETC. On issuing the Car Units, bank code as well as user's cell phone numbers will be burnt into the ROM on it. Microsoft Windows 2000, VB 6.0 and Microsoft Access are used to program and simulate the message exchange among CU, RS-TX and RS-RX under different considerations.

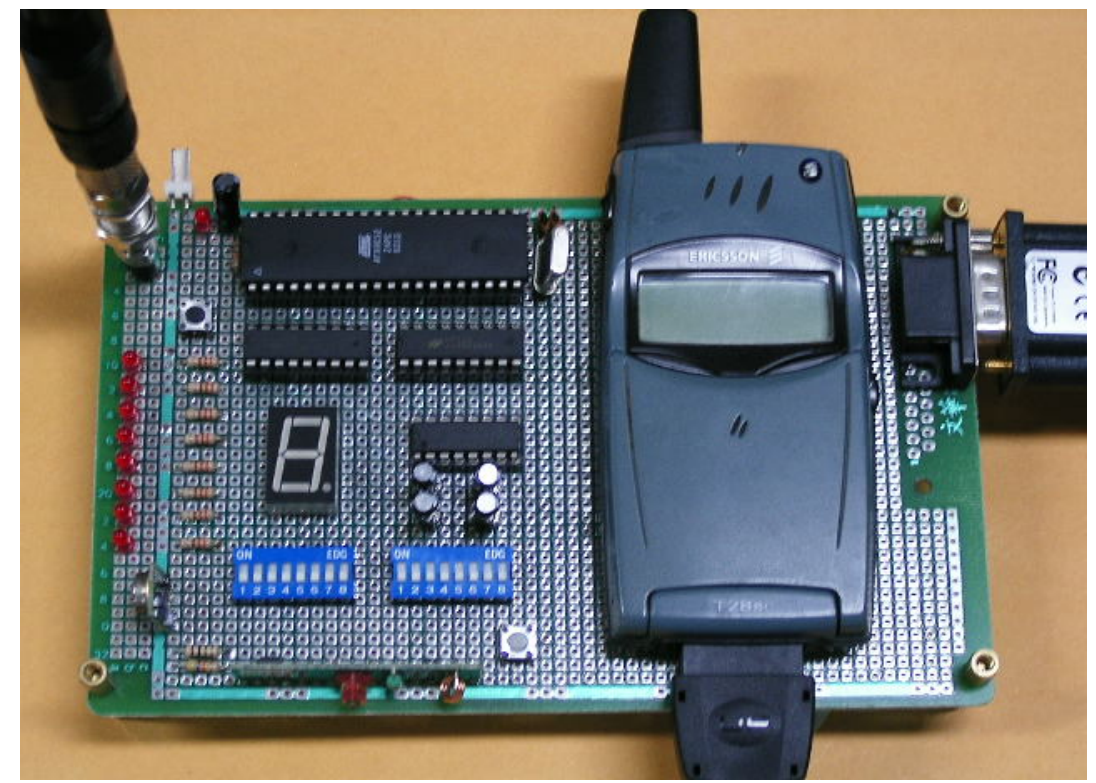

Figure 5: Hardware circuit of CU.

In reality, the microprocessor hardware and its matching firmware are suitably chosen for circuit design and fabrication in this paper. The CU, RS-RX and RS-TX architecture are shown in Figure 4 in general configuration. Circuit parts may be selected for CU, RS-TX or RS-RX. Microprocessor AT89C52 [21] is chosen to handle communication and computation control in the CU, RS-RX and RS-TX. The HT-12E is encoding the signal data in CU-TX and RS-TX for transmission. The HT-12D is decoding the signal data in CU-RX and RS-RX. The HT-12E and HT-12D have 8 address bits and 4 data bits to be used. The RS-232 port is the communication interface that is cell phone and AT89C52 [21]. AT89C52 can command cell phone by RS-232 port. In the hardware implementation, the CU, RS-TX and RS-RX are built according to the hardware designs as discussed previously. The m-ETC system hardware is installed and integrated for test as shown below diagrams of Figures $5 \sim 7$, correspondingly. From the circuit hardware, both road side units (RS-TX, RS-TX) and card units (CU) are fairly cheap to fabricate in implementation for ETC applications.

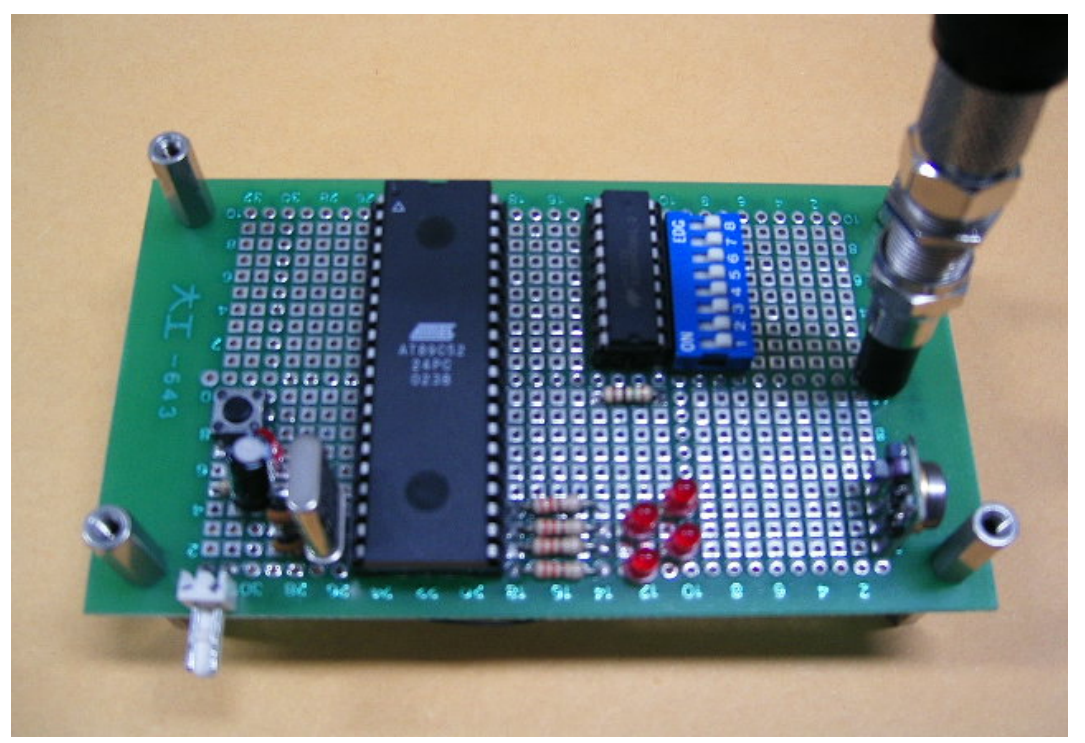

Figure 6: Hardware circuit of RS-TX. 


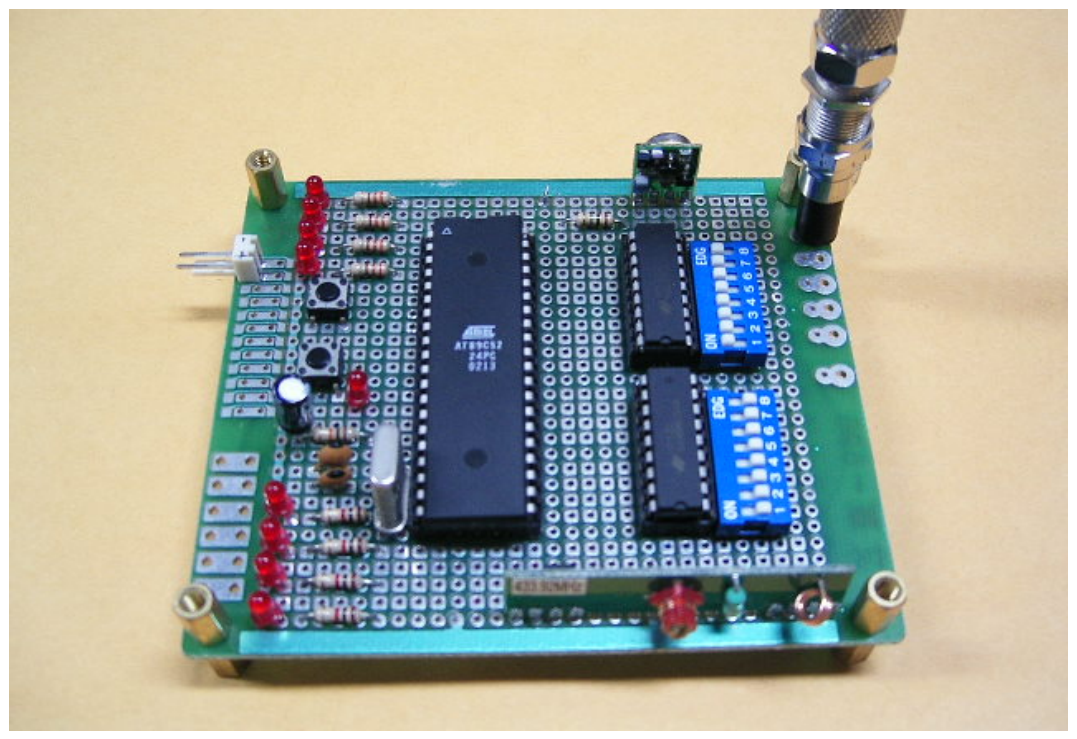

Figure 7: Hardware circuit of RS-RX.

\section{System Application in Freeway Toll}

From Figures 1 to Figure 3, the m-ETC System for freeway entrance gate control will be described in details for operation as shown in the Figure 1.

\subsection{Concept for Development}

In Taiwan, the toll system will be converted from toll station control into entrance gate control. In China, gate entrance control is most adopted on most freeways. In European countries, either toll station controls or gate entrance controls are applied. Comparing to toll station control, the toll collection process for entrance gate control is simplified in nature and has enhanced efficiency. In the proposed m-ETC, an unmanned Toll Collection e-Center will be installed with a server to accept toll payment through $\mathrm{m}$-commerce system via mobile communication. The mobile communication protocols of either the transmission control protocol in addressed IP (TCP/IP) or the point-to-point protocol (PPP) are adopted. The software will process the authentication, charge, and record in its Authorization Database.

\subsection{Definition of Basic Protocol}

There are about sixty entrance gates of along the freeways from north to south in Taiwan. Every flow control gate includes two directions with entrance and exit gates. A set of Roadside Unit at each direction of every entrance/exit gate is installed by assigning four digit code numbers for every entrance/exit gate. The Roadside Transmitter, RSTX0101 is establishing in the entrance gate in the Figure 1. The 0101 number code is an example of the entrance gate. The meaning of the first bit is direction bound, where 0 for the direction of northbound and 1 for the direction of southbound. Gate numbering starts from north to south. That means all southbound vehicles will enter from small number of control gates to larger number control gate to exit, and vice versa. The second and third bits represent the number of the flow control gate, where the tenth gate from north is used as example. The least bit stands for entrance or exit to this flow control gate, where 1 for entrance gate and 0 for exit gate. The data setting is shown in Table 1. The coding method can easily be changed on any demand with any different combination for more digits. A conversion table in embedded in the microprocessor to convert the digit number into binary code for software processing. For easy setting, dip switches (blue and white) are used as shown in the figures.

Table 1: RS-TX transmitting 4 digit data.

\begin{tabular}{|l|l|l|l|l|}
\hline Digit & 1 & 2 & 3 & 4 \\
\hline Number & $0 \sim 3$ & $0 \sim 9$ & $0 \sim 9$ & $0 \sim 1$ \\
\hline Meaning & $\begin{array}{l}\text { Bound direction } \\
0 \text { for north, 1 for } \\
\text { south, 2 for east, 3 } \\
\text { for west }\end{array}$ & $\begin{array}{l}\text { Two digit gate number in sequence } \\
\text { from south to north }\end{array}$ & $\begin{array}{l}\text { Enter or exit } \\
1 \text { for entrance, } \\
0 \text { for exit }\end{array}$ \\
\hline
\end{tabular}

In principle, since the northbound vehicles will not leave the freeway at any southbound gates, therefore, vehicles register from Gate 0101 should possibly leave from Gate 0080, which means by the four digit assignments of the first 
digit 0 as "northbound", the second and third digits 08 as "Gate 08", and the last digit 0 to "exit". Another example, the southbound vehicle enters at Gate 1101 may possibly exit to Gate 1120. The toll charge will count the traveling distance between the entrance and the exit. The first example northbound from Entrance Gate 10 to Exit Gate 08, while the second example southbound from Entrance Gate 10 to Exit Gate 12. Fare basis can be determined from the Freeway Bureau in distance-basis.

In the proposed m-ETC concept, there will be a large number of installations for Roadside Units, and the Car Units. Cost for each unit will be a great concern to the investment plan of the overall operation system.

\subsection{Example of Freeway Entrance/Exit Gate Control}

The proposed m-ETC system is organizing procedures in software to match with the hardware implementation for tests. The procedures have entrance to freeway and exit from freeway as shown in Figure 1. The roadside units are installed on the entrance or exit ramps.

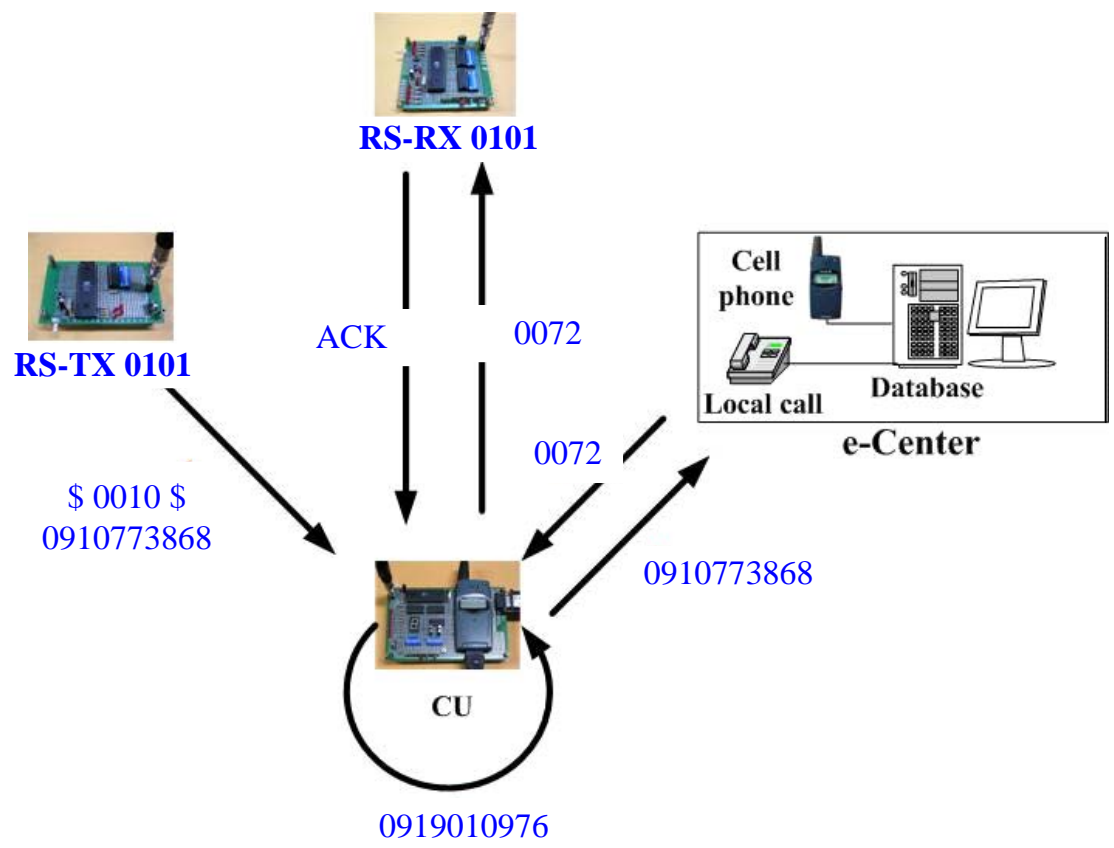

Figure 8: Procedures to enter into freeway.

\subsubsection{Entrance to Freeway}

Figure 8 shows the procedure of vehicle from entrance gate onto freeway with the following steps.

1. Step 1: The RS-TX0101 is operating on an interrogation mode to transmit a set code of 0101 and e-Center phone number at the entrance gate to the vehicles enter freeway. The RS-TX should be located near the intersection of the local way and the entrance access road with a directional antenna in focus on small areas. The "0101" is designated as the address code of this particular entrance gate. When the vehicle enters the freeway entrance access, the $\mathrm{CU}$ will receive the 0101 code and the designated e-Center phone number from CU-RX. The LED display on CU will turn from orange to red. Note, each entrance or exit gates will be assigned with different phone numbers to link with the e-Center. The gate code 1010 will direct to its database assignment.

2. Step 2: When the CU receives the 0101 code and e-Center phone number (0910773868) from RS-TX0101, the $\mathrm{CU}$ will activate the GSM cell phone to dial up to register a toll collection.

3. Step 3: The Toll Collection e-Center is always on-line to receive calls. When the mobile phone is connected, the e-Center will immediately aware of the cell phone number by incoming-call display (0919101976), the $\mathrm{CU}$ will send the RS-TX0101 code to the e-Center. The e-Center will store the registration data into database, and check with the Authorization Database. Then the e-Center will immediately reply an approval code (APC) 0072 to the CU. The entrance gate code 0101 and the approved code 0072 are written into memory device in microprocessor AT89C52 on the CU. This is the simple procedure of entrance registration. The approval code is a sequential number assigning by the e-Center microprocessor connecting to each entrance gate by 4 digits in our simulation. Approval code may possibly overlap within 
one day, however they can still be identified by the entering time. Otherwise, it might be possible to use 5 digits or more if necessary.

4. Step 4: The CU will send out the approval code on interrogation mode to RS-RX to acknowledge. The front panel will have red display turn to green for any visual inspection. The vehicle is successfully completed the entrance process to freeway. The CU will write the data into its memory as shown in Table 2.

5. Step 5: The vehicle will proceed on freeway and the green LED will be switched to orange. The data of 32 bytes to record date (ddmmyy), time (hhmmss), entrance gate code 0101 and approval code 0027 and fare basis will be stored in the memory. The e-Center will write this data into sub-database specified as "Gate 0101" in memory as shown in Table 3. In Table 3, each vehicle data takes 26 bytes from reserved 32 bytes in the simulations. Each sub-database is assigned by its entrance gate code to record the entering vehicles. This reduces the database memory size and makes easy to search while the vehicle is existing from another gate.

Table 2: Memory at CU microprocessor for this test.

\begin{tabular}{|c|c|c|c|}
\hline \multicolumn{4}{|c|}{ Memory at CU for Vehicle using 0919010976} \\
\hline Gate & Code & Date & Time \\
\hline 0101 & 0072 & 020604 & 134648 \\
\hline 0030 & 0988 & 020604 & 151341 \\
\hline
\end{tabular}

Table 3: Sub-database at e-Center for Gate 0101 and Gate 0030.

\begin{tabular}{|c|c|c|c|}
\hline \multicolumn{4}{|c|}{ Sub-database for Gate 0101 } \\
\hline APC & User by Cell phone & Date (ddmmyy) & Time (hhmmss) \\
\hline 0072 & 0919010976 & 020604 & 134648 \\
\hline 0073 & 0932977345 & 020604 & 135052 \\
\hline 0074 & 0929771991 & 020604 & 135321 \\
\hline 0075 & 0958890720 & 020604 & 135701 \\
\hline \multicolumn{4}{|c|}{ Sub-database for Gate 0030 } \\
\hline APC & User by Cell phone & Date (ddmmyy) & Time (hhmmss) \\
\hline 0988 & 0919010976 & 020604 & 151341 \\
\hline 0989 & 0933751685 & 020604 & 151522 \\
\hline 0990 & 0915872561 & 020604 & 152233 \\
\hline 0991 & 0958890720 & 020604 & 153400 \\
\hline
\end{tabular}

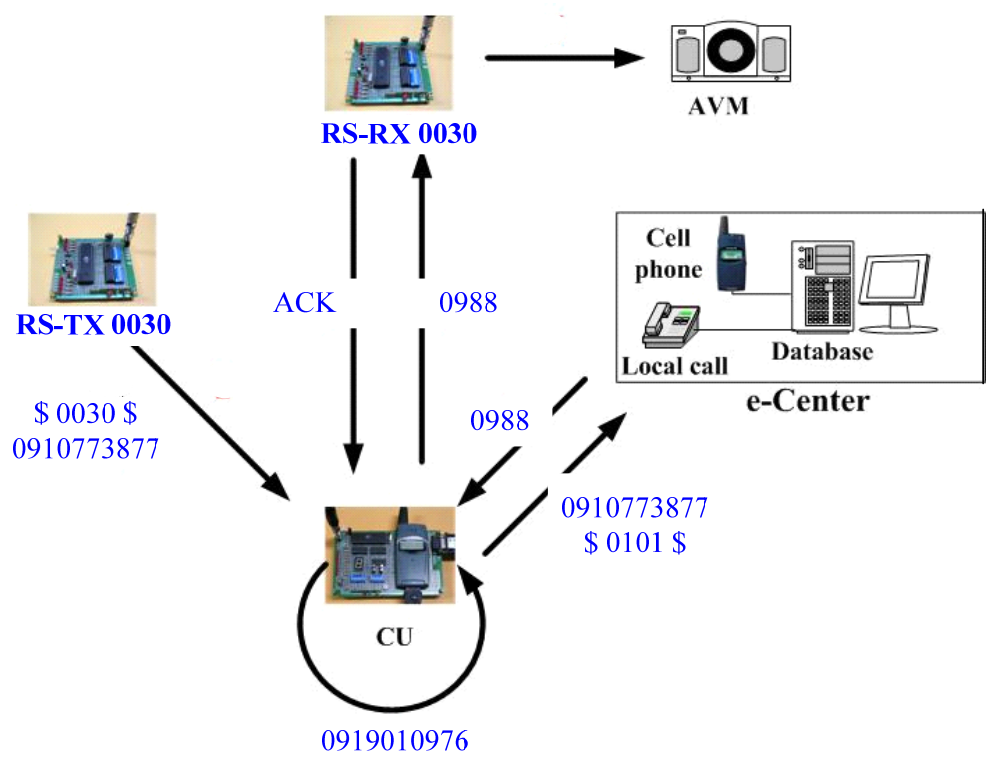

Figure 9: Procedures to exit from Freeway.

\subsubsection{Exit from Freeway}

Figure 9 shows the procedures of vehicle to exit from freeway with the following steps. 
1. Step 1: When the vehicle approaches the exit lane near the freeway, the CU will receive the interrogation 0030 code and a new e-Center phone number from RS-TX0030 near the exit. The orange LED on CU will turn to red.

2. Step 2: The CU activates the cell phone to connect to the new e-Center phone number (0910773877), and send code 0101 to specify where the vehicle enters.

3. Step 3: The e-Center receives CU with user's phone (by on-call display) and the entrance gate 0101. The software will start to trace the sub-database at Gate 0101 to find and match the vehicle using cell phone number 0919101976. The e-Center approves the toll collection from e-transaction and reply with a new approval code (APC) 0988 to the CU.

4. Step 4: The CU gets the new approval code 0988 from its cell phone and memory at the microprocessor AT89C52. The new approval code 0988 will be broadcast from CU-TX during exit to the roadside unit RSRX0300. From the tests, the signal capture time takes only $1 \mathrm{~ms}$.

5. Step 5: The RS-RX 0030 receives the interrogation 0988 and acknowledges to CU to turn on its LED from red to green. The vehicle will proceed to leave the toll freeway into local highway, the data of 32 bytes to record date (ddmmyy), time (hhmmss), exit gate code 0030 and approval code 0988 and fare basis will be stored in the memory. The CU has a memory device to write in all travel records automatically until manualclear is processed or the memory has been fully occupied. A USB interface is used in the CU to exchange memory data from external devices, such as PDA or USB memory, to send out the record. The CU memory of $512 \mathrm{kB}$ will maintain at least 8000 travel data on each travel of two 32 Bytes data as in Table 2 in the CU memory.

6. Step 6: When the vehicle exit the freeway, the toll charge will be automatically calculated. The e-Center will collect past data from all sub-databases to list all vehicles finishing e-transaction. The memory data will be transferred to the ETC Bill System to create a charge list for the bank. The ETC bill software will calculate the toll charge according to the traveling distance and fare, and taking any discharge program into account.

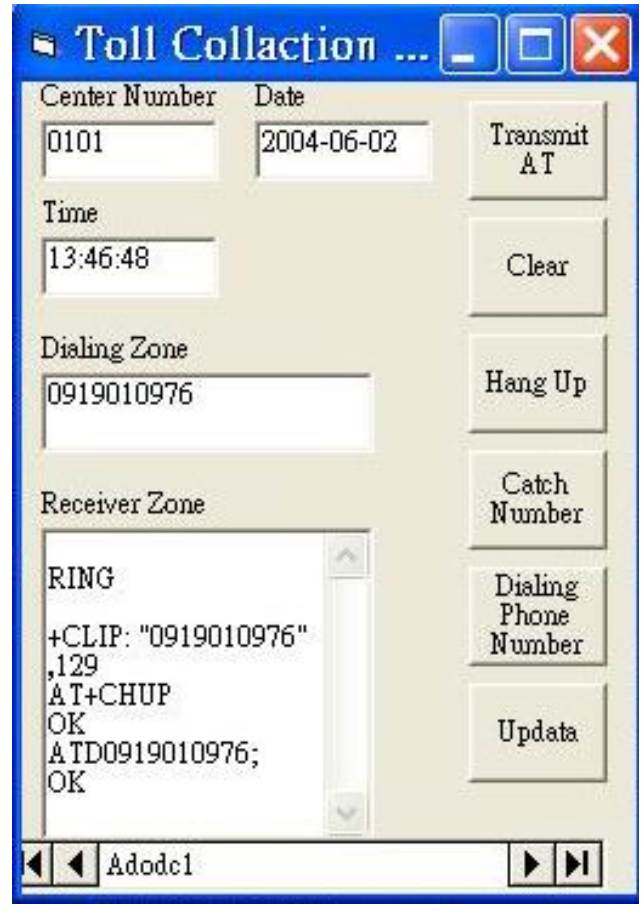

Figure 10: Display of 0919101976 at entrance gate 0101 processor.

\section{4 e-Center Authentication}

A virtual e-Center is established to handle each entrance gate and exit gate. A Tabletop PC is used to simulate the e-Center. On the campus, a simulation test in drive way is installed with two RSUs as Entrance gate 0101 and exit gate 0030 using roadside units RS-TX and RS-RX shown in Figure 6 and Figure 7. Two car units CU are built for two vehicles of 0919010976 and 0958890720 . Figure 10 shows the display of the vehicle at the entrance gate 0101 in eCenters. In the simulation test, the e-Center is connection to each gate unit by two GPRS phones, 0910773868 and 
0910773877, which are one for entrance the other for exit. It is a wireless interconnection through Internet. Detail data is shown in Table 3. The e-Center collects the CU phone number calling from the vehicle. Instantly, the eCenter sends the $A T+C L I P=1$ of $A T$ command for cell phone to enable the function to read the incoming-call display to identify the sender phone number 0919101976 and 0958890720 . The $\mathrm{CU}$ phone number will be transmitted into the database built by VB 6.0 programs as Figure 10. The CU cell phone will be disconnected automatically at receiving the approval code 0072 from RF receiver.

The m-ETC system will collect data from entrance 0101 and exit 0030 at e-Center to each relative database. Table 3 shows the designated database for Gate 0101 and Gate 0030 at e-Centers. Each phone number stands for a vehicle together with travel records on the freeway. The m-ETC bill system can calculate the fare from Gate 0101 to Gate 0030. Different free uses different fare basis or method. By the same way for vehicle user 0958890720, the charge can be calculated. The mechanism to use gate code as the sub-databases may divide the memory size into smaller and will make easy for the search for a vehicle data at the exit. While the vehicle exits the freeway, the data on Table 3 will be moved to the Bill Database at the e-Center. The memory data on each gate database are relatively very small part of total traffic on the freeway.

The CU is offered by the credit card service, bank or the system provider when the cell phone users apply for m-ETC application. There is a possibility that the vehicle driver uses different cell phone that is not the one originally registered, or different family members use the same car. An alternative may be created from the memory device to input the claimed cell phones to be used. In the CU memory, there is also a Bank Code to specify the program contract being approved. When the $\mathrm{CU}$ is connecting to a cell phone, the memory device will check the cell phone. This is a necessary process for payment authentication. In this proposal, the m-ETC charge will be combined with the mobile phone bills (as in Taiwan) or directly into bank account (as in China). Different bill process can be negotiated by ETC providers and mobile system providers in the business model.

Recently in Taiwan, the freeway toll collection system adopts microwave system for detection. It is a prepaid operation that all users should buy credit on their toll cards without any discount. The users' complaints for the unfair conditions devalue the toll collection system. For the proposed m-ETC system, e-commerce should be enforced among the allies, i. e., toll collector (freeway provider), bank, credit card service, mobile communication system providers, to share the benefits with the freeway users. The proposed m-ETC is running under unmanned condition, very little manpower for system maintenance might be required while manpower cost is always the most significant part in this business.

\section{System Application in Parking Toll}

In metropolitan areas, parking is always a serious problem. Both available land space and manpower cost have made parking lots far less than demand. Besides the fixed cost of facility investment, parking lot providers should bear significant personnel costs on lot management and fee collection. The proposed m-ETC system can be applied to unmanned parking lots for relatively low investment costs in high operation capability and efficiency. The proposed system for parking lot application may have different solutions in parking fee collection. The first solution may adopt the similar process and facility as Figure 8 and Figure 9, with some simplifications.

\subsection{Operation of the Unmanned Parking Lot}

The parking lot should be furnished with road side units on both the entrance gate and the exit gate to communicate with the parking vehicles. A parking register is equipped with a computer and connected to e-commerce data exchange center through Internet.

\subsubsection{Entering to parking lot}

Referring to Figure 10, the vehicles arrive at the entrance gate of the parking lot to proceed with the following steps.

1. Step 1: When the car approaches to the parking lot entrance gate, for example Lot No. 3715, the RS-TX at the entrance gate will broadcast its Lot No. and registration phone number, for example 3715-0910773868. This expresses a meaning for: "This is Parking Lot No. 3715, please call 0910773868 for parking".

2. Step 2: When the car unit receives the broadcast, and will activate the CU to dial 09010773868 for parking lot registration.

3. Step 3: The register reads the incoming-call phone number, i. e., 0919101976, proceeds to record this number, and reply with an approved code (APC), for example 0917, and time to accept the parking registration.

4. Step 4: The register will acknowledge the RS-RX at the entrance gate with the registration. 
5. Step 5: If the entrance gate is distance away, the car will proceed to the entrance gate and transmits the APC 0917 to open the gate. Otherwise, if the distance is short, the entrance gate will open to allow this vehicle to enter.

6. Step 6: The register will save the parking registration on its computer and e-Center, with the information of registration cell phone number, approved code and entering time. A 32 byte data is created and stored.

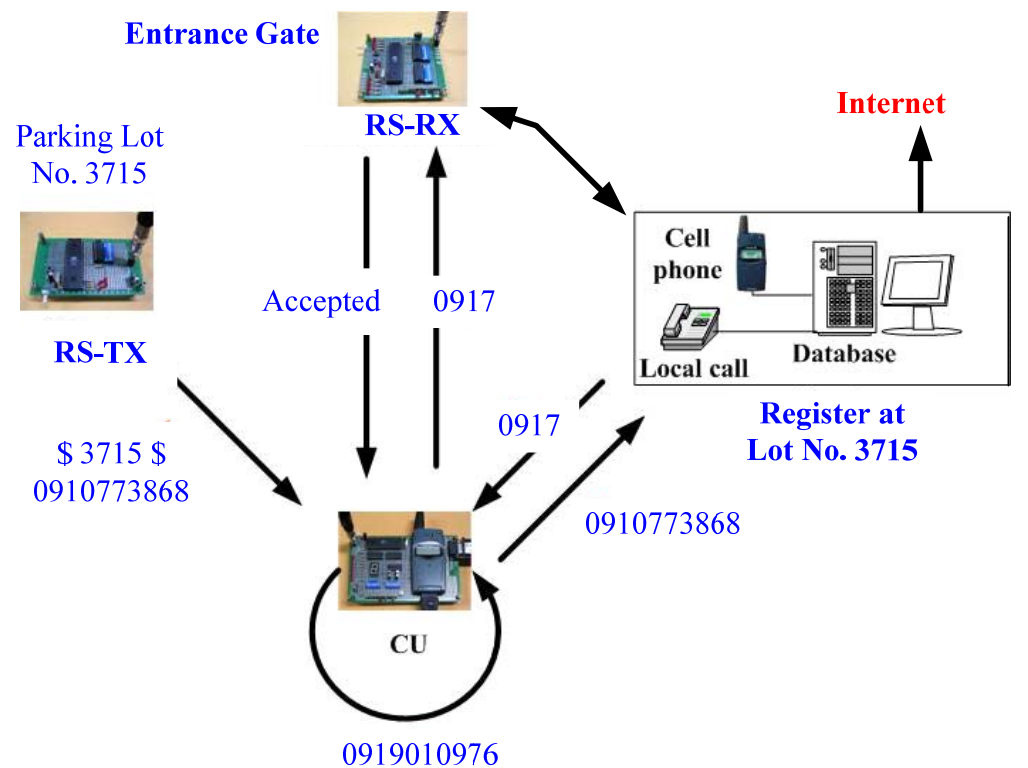

Figure 11: Procedures to enter an unmanned parking lot.

\subsubsection{Leaving from parking lot}

Referring to Figure11, the vehicles leave from the parking lot to proceed with the following steps at the exit gate.

1. Step 1: Whenever the car is ready to leave, the car unit will redial to the register at 0919773868 with the registration code, 0917, to request for departure.

2. Step 2: If the car user forgets to recall the register, and the vehicle arrives to the exit gate. The RS-TX at the exit gate will send the interrogation to activate the car unit. The car unit will proceed to Step 1.

3. Step 3: The register receives the incoming call number to match with the approved code, and replies to the car unit with an acknowledgement. Also the register sends the approved code0917 to the RS-RX at the exit gate to allow 0917 to exit. This is a security assurance process in the parking lot.

4. Step 4: The car unit sends the approved code to the RS-RX. The RS-RX at the exit gate receives registration approved code, 0917, and reply to the car unit with exit time and opens the gate. At the same time, the RS-RX will communicate with the register computer with the vehicle's approved code and its departing time.

5. Step 5: The register computer will collect the parking information to match the approved code, 0917, with the previous data, and generate a parking fee charge into the memory.

6. Step 6: The register computer at parking lot No. 3715 will edit the charge file, and connect to the mobile phone system provider to access the charge process to the registered bank account through Internet. An ecommerce authentication and transaction system is required. 


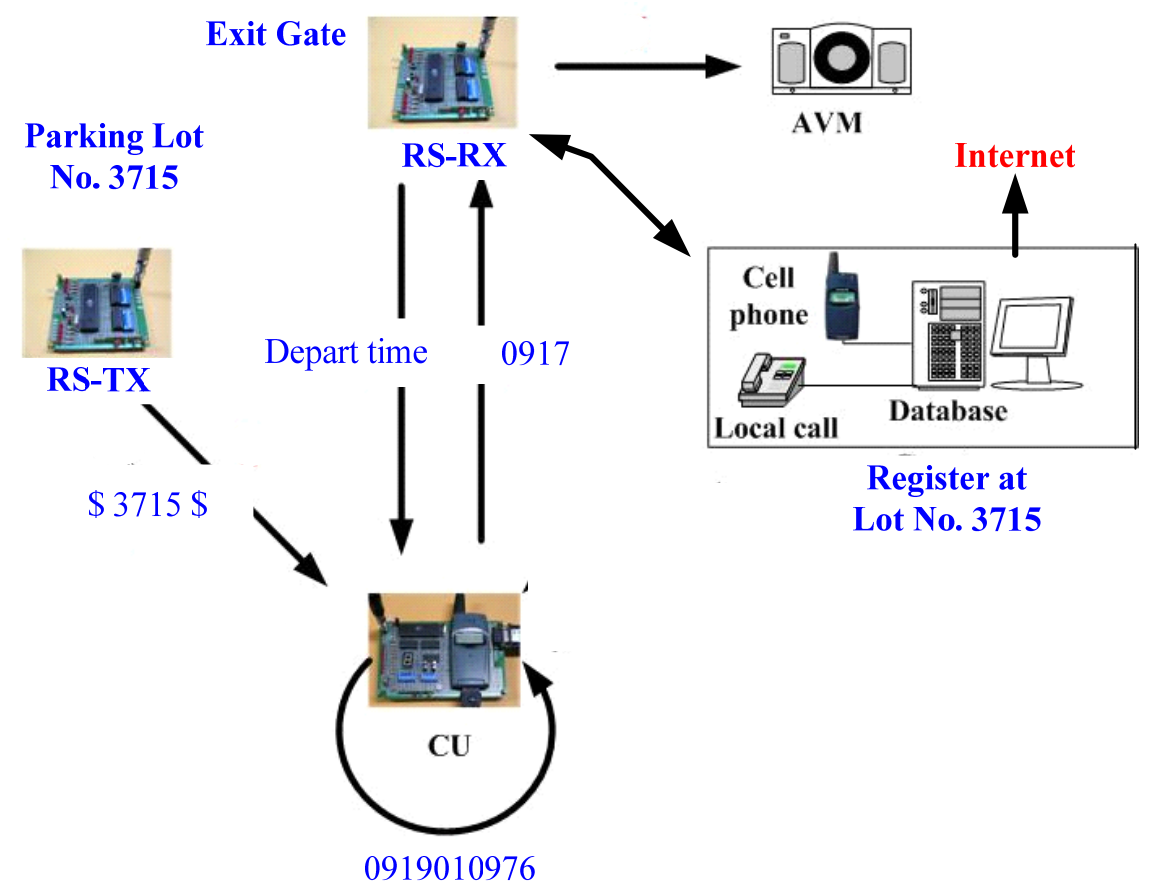

Figure 12: Procedures to exit from an unmanned parking lot.

\subsection{Parking lot register computer}

The parking lot register computer will need a data base management and file generator to collect the parking data on hour basis and daily basis, and store into memory devices. The parking lot register computer will connect to the eCenter of bank charge system through Internet. This process is different from freeway toll, since most parking lots are owned by individuals or investment companies. Since the proposed system adopts mobile communication, the mobile phone system provider should be involved together with the credit card bank. There is an e-commerce system to be constructed on the toll and fee collection bases.

The capital investment for a parking lot is very small compared to the value of the land piece. Two sets of road side units, RS-RX and RS-TX, and a personal computer with data base management software are required to connect to Bank e-transaction system through Internet. The parking space can simply be furnished by pavement with track marks. In most cases, the parking space is a temporary investment before a construction project is launched. Therefore less investment cost will encourage land owners to be willing to go for parking business.

\section{Test and Verification}

The system verification is carried out on campus with preparations of hardware and firmware. The test circuits, as shown in Figures 5, 6, 7, are completed on breadboards that make easy for changes and modifications during tests. The test environment is set up on campus with one straight road to speed up the car to $60 \mathrm{~km}$ and a curve road to simulate a ramp onto freeway. Tests verify the RF signal interaction between RSU and CU by more than hundred runs. The RF signal is tuned to be effective for 30 50 meters. Repeated tests confirm that within this range RSU-RX and RSU-TX can 100\% capture the signal from CU. The transmitting message is as short as 32 bytes. The transmission time is within $5 \mathrm{~ms}$ at 4800 bps baud rate. There are some remarks to mention as follows:

1. The GSM connection time from receiving the RS-TX interrogation is 5 to 12 seconds. Among the tests, $95 \%$ of population falls within 7 seconds. The normal travel distance for a vehicle at the ramp is from 55 to 133 meters, where the ramp distance is always longer than 300 meters in Taiwan. The CU processes the reply interrogation to RS-RX takes 0.01 seconds $(10 \mathrm{~ms})$, and then writes the approval code and time into the memory device. This will keep a personal record for bill reference.

2. In our tests, the roadside units are connecting GPRS modules to link with e-Center on Internet, that no additional engineering work for wiring is necessary. The roadside units have to pay GPRS fee based on transmission volume. Presently, GPRS monthly basic rate for 30 MB is US\$ 10 in Taiwan. 30 MB is good for handling 125,000 vehicles. The rate can be extended to unlimited capacity. Reversely, one transaction 
for each vehicle is 0.008 US $\$$, or 0.016 US $\$$ per freeway trip (on and off the freeway entrance). The same GPRS service is Southern China 30 MB for US $\$ 4$.

3. When entering the freeway, the car ID using cell phone number will be written into the sub-database for this entrance gate, Gate 0030 for example. At the exit, when the vehicle connects to e-Center database, it will search to the sub-database under the entrance gate number, Gate 0030 for example. Database search is 2 ms for 200 vehicles in our simulation. This means there are 200 vehicles entering to this freeway from Gate 0030 heading the same direction (heading north for example). The traveling time for $300 \mathrm{~m}$ exit ramp is long enough for GSM connection and database search to finish this process for toll charge.

4. In the parking lot applications, there is less concern on vehicle speed and GSM connecting time. However, system reliability and efficiency is very important to support the unmanned parking lot operation. In the tests, failure rate is less than 2 in 1000 tests. The failure happens at the exit that the user should send his request again to complete transaction. GSM quality is almost excellent in metropolitan area, where parking lots are mostly demanded.

5. There is no mobile phone charge for the use of the proposed m-ETC, since the incoming-call number identification is programmed in the e-Center software. The proposed parking lot application can offer a discount plan to commerce users. In Taiwan, $5 \%$ discount is directly applied for frequent users. Many countries apply discount fare to different contract programs.

6. The car users can download the historical records of the toll charges from the CU memory. The memory is $512 \mathrm{kB}$ for at least 8000 travel data.

\section{Business Model}

The propose Mobile Electronic Toll Collection needs to establish a new business model for real operation. Figure 12 shows the proposed business model to link banks, credit card services, mobile system providers, toll service providers with general public users. There is a constraint to start the ETC that the users should sign up applications by different programs to get approval and receive a car unit for use. The sign up applications can be through (1) open a bank account to register cell phone, (2) apply a new credit card service with cell phone, (3) apply a new cell phone to start new program. Either program being approved and contracted, the users commit to the bill and charge interaction in ETC. Under the program contract, the users may pay the toll bills monthly through a credit card or any other bank transaction means.

On the business side, there are allied organization from banks, credit card services, and mobile system providers to sign up agreement with the ETC. All users' data should be released on an "Authorization Database" for real time authentication through Internet. The Allies start the ETC business by individually contract to all toll service providers. There are two types of toll service providers: (1) the public investments, such as freeway, parking lot, bridge, ferry, or tunnel; (2) the private investments, such as parking lots, and any mobile payments. Bank is the final bill collection and distributes service charge to the business Allies and the toll service providers.

On issuing the car unit, there is an embedded code burnt in the microprocessor memory. This code includes the contract bank and committed cell phone numbers. Once the user's cell phone is connected onto the car unit, the microprocessor will check the committed cell phones to allow the proper user. On the mobile registration, the car unit will dial to the e-Center for authentication from the Authorization Database. On the authentication process, the "incoming-call display" will be read and check with the authorization database. In the Authorization Database, all numbers are queuing by decimal codes. From the test, search process from the million data authorization database takes 1 10 seconds to find a register user data.

There are a lot of dead debts from mobile phone bill that hesitate the mobile system provider to aggressively join this development. However, the proposed business model introduces credit or bank involvement to enforce credit transaction and reduce the risk of dead debts to minimum. Mobile phone system providers support system infrastructure to run the proposed business model for m-ETC. Mobile communication offers very high reliable ad very popularized wireless communication services will also enhance the overall e-commerce performance. In the proposed m-ETC, user hardware of CU can only be issued from the bank after credit survey. This can be another protection line to screen off the bad credit applicants. CU hardware prevents bad debits. 


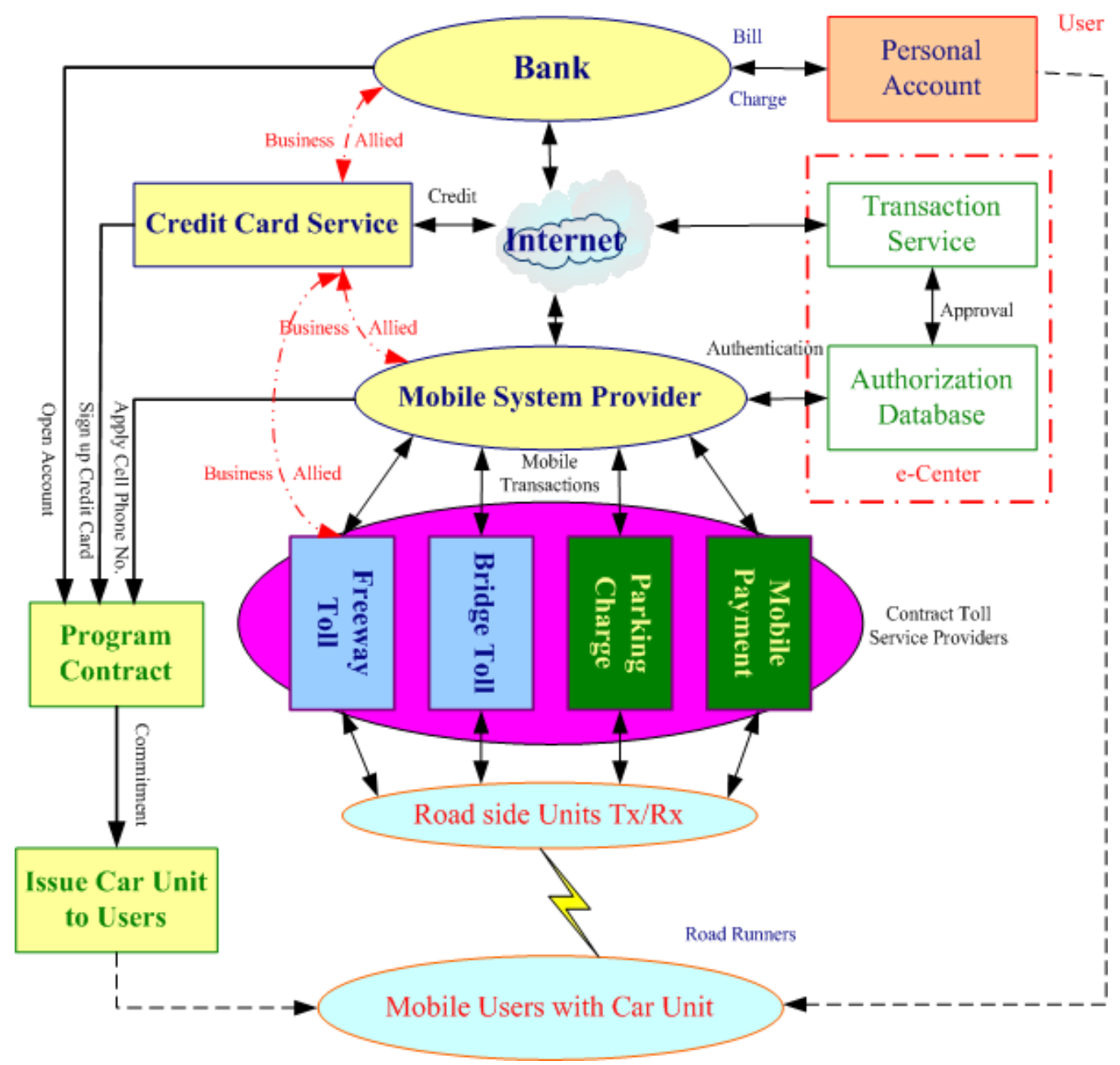

Figure 13: Business model for the proposed mobile electronic toll collection.

\section{Discussion}

In this paper, a general purpose mobile electronic toll collection (m-ETC) system is proposed for both technology and management solutions. The business model for the proposed m-ETC system is also presented. The proposed system has accomplished three main goals, the first for the overall system concept, the second for the hardware design, and the third for the matching software and firmware implementation. The system integrates mobile communication with RF communication into successful design and fabrication, implementation on hardware, software and firmware in toll interaction on freeways or parking lots. The hardware cost from the prototype demonstration system is very low cost to provide high reliability and stability services. From laboratory estimation, the investment cost for Freeway 1 in Taiwan is calculated. The total mileage is $366 \mathrm{~km}$ with 10 toll stations. Each station needs the facilities as listed in Table 4. Each toll station demands US $\$ 12,000$ to reduce 4 toll operators. For Freeway 1, the investment is 10 toll stations plus the central server and e-commerce operation facilities, which is approximate US\$300,000 for initial run ETC in partial operator. As compared to Australian [17] and Canadian [18] ETC investments with billion dollar scale, the proposed system is quite low to solve the ITS toll collection problems.

Table 4: System cost breakdown for an m-ETC station in Taiwan.

\begin{tabular}{|l|l|l|l|l|l|}
\hline Item & RSU-Tx & RSU-Rx & $\begin{array}{l}\text { Local } \\
\text { Server }\end{array}$ & $\begin{array}{l}\text { Supporting } \\
\text { system }\end{array}$ & $\begin{array}{l}\text { Setup } \\
\text { Engineering }\end{array}$ \\
\hline Number & 4 & 4 & 1 & 1 & 1 \\
\hline Unit Cost (US\$) & 500 & 500 & 2500 & 2000 & 3500 \\
\hline Subtotal & 2000 & 2000 & 2500 & 2000 & 3500 \\
\hline Description: Each 2 lane 2 way toll station has total cost of US\$ 12,000. \\
\hline
\end{tabular}

For an m-ETC parking lot, the investment is relative low. It requires only two pairs of RSU-Tx and RSU-Rx, and an eCenter server for a parking lot as shown in Table 5 . The total estimation will be US\$ 6,500. Once a lot is available, with just a few days work, the m-ETC parking lot can be launched into service. 
Table 5: Cost breakdown for an m-ETC parking lot.

\begin{tabular}{|l|l|l|l|l|l|}
\hline Item & RSU-Tx & RSU-Rx & $\begin{array}{l}\text { Local } \\
\text { Server }\end{array}$ & $\begin{array}{l}\text { Supporting } \\
\text { System }\end{array}$ & $\begin{array}{l}\text { Setup } \\
\text { Engineering }\end{array}$ \\
\hline Number & 2 & 2 & 1 & 1 & 1 \\
\hline Unit Cost (US\$) & 500 & 500 & 2500 & 1000 & 1000 \\
\hline Subtotal & 1000 & 1000 & 2500 & 1000 & 1000 \\
\hline $\begin{array}{l}\text { Description: An unmanned parking lot has total cost of US\$ 6,500, plus lot pavement, ground } \\
\text { marking and gate. }\end{array}$
\end{tabular}

For toll collection registration, each mobile phone call does not need to make an actual connection, since the register needs only to read the incoming call phone number, records this phone number and the time, and disconnects. There is no mobile phone bill to the users at all. The use of mobile communication in toll collection is very viable and attractive.

To keep transaction records, the car unit has embedded a memory device to record all the charge interactions. Each recorded data is 32 bytes containing 12 bytes for time (in and out), 8 bytes for charge station, 4 bytes for bill, and 8 bytes for other marks. Each travel or parking requires two 32 bytes data for 64 bytes. The $512 \mathrm{kB}$ memory device in the car unit can keep as much as 8000 ETC transaction records. In general, this means the uses can keep toll records for years. The memory device can be detached from the car unit and read from personal computers or PDAs.

At present, mobile phone users have become extremely high population. The adoption of mobile communication is a developing trend for wider varieties of added-value applications. The proposed m-ETC system will need a joint venture and cooperation from freeway authorities, land owners, mobile communication system providers, credit card services, banks and investment companies. To prevent bad debts from mobile communication users, different programs similar to prepaid phone can be applied. In China, mobile communication system providers are cooperative with credit card issue banks to directly link the charge system into personal saving account. This is a very good commerce structure to prevent bad debt.

For e-commerce authentication concerns, the mobile phone users should get certain clearance to pay charges on a registered cell phone. Since the users require a car unit to interact with the proposed mobile toll collection system, the car unit $(\mathrm{CU})$ can be regarded as a good means for constraints. In the proposed m-ETC system, since the car unit costs less than US\$35, it might be possible to be used as a gift to the ETC users from the credit card issuing banks after sign up the charge and payment agreement and commitment. As the car unit memory will burn in personal data after the contract, the e-commerce authentication can be guaranteed. The next issue of e-commerce transaction process in conjunction with mobile phones to credit card issuing banks should be a simple internal problem to deal with. One additional function for authentication may use the memory device in the car unit to keep a bank authentication code. On each toll registration, this code should be sent to the register computer. This mechanism can be designed in software.

The car unit should require a cell phone for communication. In the car unit memory, there are bank codes and cell phones burnt in for individualization. On each time of use, the car unit will check with the cell phone number. Once the cell phone is removed from the car unit, any other cell phones will never activate the car unit for ETC interaction. In the parking lot applications, this is a security assurance for the parking users to keep from car burglar.

In the developing and developed countries, mobile phone users have already become the largest consumer market. The added-value of mobile communication should be studied and developed in all respects. The proposed $\mathrm{m}$-ETC can become a new promotion program of mobile communication in its added values. Although mobile system providers will not receive direct mobile access, however, the infrastructure support to the ETC transaction will still be benefit from the program. On the electronic toll collection, 15 percent of overall toll charge can be allocate to the ETC allies, such as mobile system providers and credit card banks.

M-commerce is a rising technology that most applications may be directed into possible connection with mobile phones. As for today, GSM, GPRS, 3G or even B3G technologies are still expanding. However, GSM for voice is still the most profitable system at all. There are some defeats in GSM services such as minor chance of congestion, some unavailable area, and significant longer delay at SMS (short message service). In recent years, mobile Internet has become a reality [1]. While mobile communications for e-transaction can be realizable, mobile Internet is also expecting through mobile communication. Mobile communications of $2.5 \mathrm{G}$ (2.5 Generation of General Packet Radio Service, GPRS) as well as 3G and B3G (Third Generation and Beyond Third Generation) are available and mature to connect onto Internet. Taking the known defeats into account, the ETC is still most convenient system to develop. Further tests on reliability and stability for the proposal m-ETC mechanism may be required.

Presently, the proposed m-ETC requires a CU to connect to the toll collection system through users' mobile phone. Different types of cell phones use different data connectors. There will be a necessary design of standard CU output connector, such as RS232 to fit for all types of cell phone connectors. In the future, mini USB (universal serial bus) 
connector can possibly become a new standard to the cell phones, and can be the solution to the $\mathrm{CU}$ in the proposed m-ETC applications.

In our tests, the proposed m-ETC system has acceptable time delays with reduced-size database design. The overall test efficiency is excellent. The system performance on CU to RSU can easily match by the RF module with high reliability. The reliability of mobile base station transceiver (BTS) is good enough to offer ETC service since each GSM link requires no actual connection.

\section{Conclusion}

The proposed mobile electronic toll collection system is verified from hardware fabrication and implementation with simulation tests. The test data show that the proposed technique is useful to create a new concept of mobile ecommerce to enhance the mobile phone users. From point of view of the freeway operators, the banks or the system providers, the proposed m-ETC will reduce significant manpower cost to shift into discount plans or user feedback plans. Considering the proposed system technology in this paper, the hardware cost is fairly low for any investment on the proposed m-ETC projects. The cost of car unit may be dropped to half for mass production. To attract the users, the car unit $(\mathrm{CU})$ can be a free gift under sign up the program contract. In addition, since the proposed m-ETC will not generate any cost from mobile phone users, the facilitation and convenience will be the most benefit to the public.

In comparison to many different ETC solutions, such as microwave or RFID, the proposed m-ETC is the most economic system to establish for least investment, least engineering construction, least communication infrastructure, and maximum adoptions. In marketing concept, once the m-ETC has become a popular application for many different toll collection systems, the mobile phone manufacture will use generalized standard to design their new cell phones. Current bottleneck on the connection between CU to cell phones will be solved.

To adopt the proposed technology, m-ETC parking lot can be the early phase implementation in metropolitan. Since very small investment can achieve a full unmanned parking lot operation, any idle or unused land lots can be converted into parking lot. Least investment, quick conversion can be attractive to bank investment in cooperation with the land owners. In addition, the proposed system hardware is $100 \%$ reusable to any sites.

\section{Acknowledgments}

The proposed m-ETC has been recognized and approved by Taiwanese Patent: Invention No. 173466. This work is partial result supporting from NSC project under contract NSC92-2218-E018-004.

\section{Websites List}

Site 1: National Communications Commission http://www.ncc.gov.tw

\section{References}

[1] A. E. Ambrosch, Applied telematics - What makes the world's largest electronic tolling system work, Elektrotechnik und Informationstechnik, vol. 122, no. 4, pp. a19-a22, 2005.

[2] J. J. Carr, Sensors and Circuits, NJ: Prentice-Hall PTR, 1993.

[3] A. Christoffer, GPRS and 3G Wireless Applications. NY: John Wiley \& Sons, 2001.

[4] B. V. Education, Mobile Networking with WAP, Braunschweig: Vieweg, 2000.

[5] M. Fujise, Radio over fiber transmission technology for ITS and mobile communications, IEICE Transactions on Fundamentals of Electronics, Communications and Computer Sciences, vol. E84A, no. 8, pp. 1808-1814, August 2001.

[6] W. Grabow, T. Wixforth, H. Ziegler, $5.8 \mathrm{GHz}$ phase array antenna for electronic toll collection in road traffic applications, in Proceedings of the 1996 IEEE-MTT-S International Microwave Symposium Digest, San Francisco, 1996, vol. 1, pp. 325-328.

[7] H. Gunnar, GSM Networks: Protocols, Terminology and Implementation, US: Artech House Publishers, 1998.

[8] Intelligent Transportation System, US Department of Transportation (2004), [Online]. Available: http://www.its.dot.gov/arch/index.htm.

[9] T. Joachim, The GSM Network: GPRS Evolution: One Step toward UMTS, Taiwan: John Wiley \& Sons, 2001.

[10] E. Jorg, GSM Switching, Services and Protocols, NY: John Wiley \& Sons, 2001.

[11] H. Kurihara, Y. Hirai, K. Takizawa, T. Iwata, O. Hashimoto, An improvement of communication environment for ETC system by using transparent em wave absorber, IEICE Transactions on Electronics, vol. E88-C, no. 12, pp. 2350-2357, December 2005.

[12] F. Mueller-Veerese, Mobile Commerce Report, London: Durlacher Research Ltd, 2000. 
[13] Siemens, (2004). AT Command Set of SIEMENS MC3.'5 module, [Online]. Available: http://www.cnetek.net/down/mc35 atc 01 v0500.pdf.

[14] Y. H. Song, Discuss to electronic toll collection and technical standard, Journal of Highway and Transportation Research and Development, vol. 19, no. 5, pp. 103-109, May 2002.

[15] C. Swedberg, (2004). RFID Drives Highway Traffic Reports, RFID Journal, [Online]. Available: http://www.rfidjournal.com/article/articlereview/1243/1/1.

[16] P. Tarasewich, R. C. Nickerson, M. Warkentin, Issues in mobile E-Commerce, Communications of the Association for Information, vol. 8, pp. 41-64, January 2002.

[17] The City Link Toll Road, Melbourne, Australia (2005), [Online]. Available: http://www.roadtraffic-technology.com/ projects/melbourne citylink.

[18] The 407 Express Toll Route (ETR), Ontario, Canada (2006), [Online]. Available: http://www.roadtraffictechnology.com/projects/407.

[19] U. Varshney, Location management for mobile commerce applications in wireless Internet environment, ACM Transactions on Internet Technology, 1073-0516/01/0300-0034, 2001.

[20] A. Visser, H. H. Yakali, A. J. van der Wees, M. Oud, G. A. van der Spek, L. O. Hertzberger, A hierarchical view on modeling the reliability of a DSRC link for ETC applications, IEEE Transactions on Intelligent Transportation Systems, vol. 3, no. 2, pp. 120 - 129, June 2002.

[21] Wikipedia Foundation, Inc., RFID system technology, (2007). [Online]. Available: http://en.wikipedia.org/wiki/ RFID. 